\title{
Quarantine Reflections: Virtual Clerkships, Real Patients
}

Monica Soni ${ }^{1}$

${ }^{1}$ Georgetown University School of Medicine

Keywords: clinical rotations, covid-19

https://doi.org/10.52504/001c.13647

Georgetown Medical Review

Vol. 4, Issue 1, 2020

\begin{abstract}
During my first year of medical school, an encounter involving something as simple as measuring a patient's BMI left me blindsided. But it taught me, in a very visceral way, about the complexity of the profession into which we have entered. As we progress through our "virtual clerkships" for the time being, let us not forget about the very real patients who have shaped our journeys thus far.
\end{abstract}

As my classmates and I await our return to campus and the much-anticipated start of clinical rotations, I can't help but use this quarantine to reflect on some of my past clinical experiences during medical school thus far. I've had the privilege of playing a small role in the care of a handful of patients, and I can remember stories, faces and names-but usually not all three. However, there is one individual I remember very clearly.

Her name was L.B. and we met my first year of medical school through the Community Based Learning experience. My team and I had been assigned to volunteer at an apartment complex that serves low-income residents, and we were hosting a session called Know Your Numbers. Our goal was to measure some basic vital signs-blood pressure, heart rate, respiratory rate-in addition to measuring BMI and body fat percentage using a bioelectrical impedance monitor. We had just learned about the dangers of uncontrolled hypertension, so this event had taken on a new level of importance for us-we were determined to screen and educate every resident we could.

At that point, I still couldn't measure blood pressure with any semblance of grace, so I volunteered to help with the bioelectrical impedance monitor. However, I soon realized I was not prepared for that task either.

L.B. arrived at the event with her husband on one arm and a grocery bag full of all her medicines on the other. She had the biggest smile as she entered the room, and I could immediately tell she was a very kind woman, full of life. I greeted her and we made our way to some chairs near a window. We chatted for a few minutes and then she handed me the grocery bag, asking all sorts of questions. As I looked through her medicines, I saw words I recognized-Spironolactone, Lasix, the 'pril' ending of an ACE inhibitor! I was even able to answer some of her questions, which renewed my spirit in preparation for my inevitable return to the library later that evening. 
Next, I helped L.B. with the impedance monitor. After waiting for the machine to compute her BMI, the number 64 flashed abruptly on the screen and whatever sense of comfort I felt quickly vanished. I didn't know what to say-this value was way off the chart of BMI values I had loaded onto my phone to help the residents visually interpret their data. L.B. looked at the number and then looked at me, asking excitedly in her cheery voice, "Is that good?”

No, it wasn't.

I didn't know where to begin. Voice trembling, I started to discuss the purpose of BMI as a measure. I then showed L.B. the BMI chart and explained that her value of 64 fell within the category of Extremely Obese. I knew this would be difficult to hear, so I tried to deliver the news slowly and softly, but it wasn't long before her eyes began to well with tears. I gave her a hug and chatted with her for a while, trying to reassure her-and hoping to see her carefree smile once more. After feeling utterly defeated, I called over one of the family medicine physicians so he could better counsel her.

In that moment, it was clear in a very visceral way that being a physician was so much more complex and multi-layered than I truly appreciated. In that moment, it didn't matter that I knew Spironolactone's mechanism of action, or that I understood how to calculate BMI. None of that mattered because my patient was struggling and I didn't know how to help her. And to think that this experience was far removed from the chaos, stress and emotion of the hospital; far removed from the life-altering diagnoses and test results that will mark our days on the wards.

As my classmates and I continue our "virtual clerkships" for the time being, let us not forget that everything we do is for the patient. Let us not forget what a gift it is to be able to sit with patients, to hold their hands, to accompany them in person on their journey-even if just for a few minutes. Soon enough, we will resume our clinical roles and be expected to counsel, support, comfort, motivate, educate-and, most importantly, listen. We must never forget that these are our most important tools. 